\title{
Feasibility investigation of a smart thermo- acoustic configuration for general aviation aircrafts
}

\author{
Massimo Viscardi ${ }^{1}$, Maurizio Arena ${ }^{1, *}$, Valerio Porpora ${ }^{2}$, Giuliano Di Paola ${ }^{2}$, and Edoardo \\ Aubry $^{3}$ \\ ${ }^{1}$ Department of Industrial Engineering - Aerospace section, University of Naples "Federico II", \\ Via Claudio, 21, Naples, 80125, Italy \\ ${ }^{2}$ Protom Group S.p.A., Aerospace division, Via Vicinale S.M. del Pianto - CPN, Ed. 680143 - \\ Naples, Italy \\ ${ }^{3}$ TI\&A Tecnologie Industriali ed Aeronautiche, Via Colle - Somma Vesuviana 80049, Naples, Italy
}

\begin{abstract}
One of the most disturbing noise for passengers is related to the engine fan. This noise is mainly tonal and in the low-frequency range. Reducing its impact for the comfort of passengers is an important and challenging issue in aeronautics. One suitable way to reduce cabin noise is to use efficient thermal acoustic insulation blankets between the interior trim panel and the exterior shell. General Aviation Aircrafts, are generally equipped with a cabin poorly efficient both in terms of thermal and acoustic insulation; this due mainly to the not availability of the most innovative solutions or materials like those used on Large Passenger Aircraft. In this context the authors have faced this crucial issue within SPAIN Project "Smart Panels for SAT Aircrafts Cabin Insulation" which makes part of the Systems Integrated Technology Demonstrator (ITD) Program in EU Clean Sky 2. This project aims scientific and technological breakthroughs in the development and validation of new insulation treatments used in aircraft developing a thermo-acoustic insulation system with materials and innovative solutions highly efficient at an affordable cost for this class of aircrafts. According to the available materials on the market with high thermal and acoustic individual performance, SPAIN goal is to design, develop and test an efficient insulation panel suitable for the General Aviation Aircraft compliant with the technical specification in terms of and weight to performance, and cost to performance aspects. Another item that has been strongly worked on, is the integration technology of this solution with the actual interiors configuration with specific focus to maintenance aspects. A set of sandwich configurations have been designed for each specific area of the fuselage to fulfil the overall noise level target; preliminary test have been performed at coupon level and sub-assembly level to confirm the expected outcomes.
\end{abstract}

\footnotetext{
* Corresponding author: massimo.viscardi@unina.it
} 


\section{Introduction}

The general aviation industry is becoming more and more demanding towards the improvement of internal comfort. Aircraft cabin issues are taking an increasingly main role in influencing the acoustic and thermal comfort level of passengers, [1-2]. Leading aircraft companies, such as Boeing and Airbus, have been improving the comfort level of their cabins in order to meet such demand. The Clean Sky 2 research platform represents currently a real opportunity to develop innovative solutions for the new generation of aircraft, [3]. In this perspective, SPAIN Project has the purpose to improve the acoustic and thermal insulation for General Aviation Aircrafts and more in general for the Small Aircraft Transportation (SAT) community by providing a performant, cost effective and lightweight cabin insulation system linked to the Cabin lining panels instead of primary fuselage structure (skin) to simplify maintenance operations. The Topic manager of the project is the Czech aircraft manufacturer Evektor, which provided the objectives in terms of unit heat resistance $\left(1.411 \mathrm{~m}^{2} \mathrm{~K} / \mathrm{W}\right)$, sound level in the cabin $(80 \mathrm{dBA})$ and weight of the system (about $40 \mathrm{Kg}$ ). The companies involved in the project are Protom, with rules of project Coordinator and system design and TI\&A partner for the construction and installation of the insulation system on a demonstrator (EV-55 aircraft). An aim of this activity is to provide a set of data for design of sound and thermal insulation of the fuselage of small aircraft. Final design will be verified on a demonstrator imitating the aircraft fuselage. Moreover results of preliminary noise and vibration measurements will be presented here. These measurements were realized by EVEKTOR on the EV-55 airplane, [4]. For concept and design of heat insulation results of heat balance analysis can be used. This thermal analysis is based on the heat exchange equivalence between outer environment and interior of the airplane with defined temperatures.

\section{Thermal balance of the aircraft cabin}

\subsection{Boundary conditions}

Thermal insulation is used to reduce heat losses from the cabin to the surroundings. These insulation layers often play the role in thermal as well as in noise insulation, Figure 1. Requirements for insulation in the aircraft are following, [5]:

- Thermal, noise and fire resistance;

- Low weight;

- Not electrically conductive;

- Not causing corrosion of neighbouring structures;

- Must allow inspection of the fuselage structure;

- Must not absorb large amount of water;

- Must not have adverse environmental and/or healthy/safety effects during fabrication and installation, or in service use and disposal;

- Must fulfil requirements of CS23 / FAR23 regulations. 


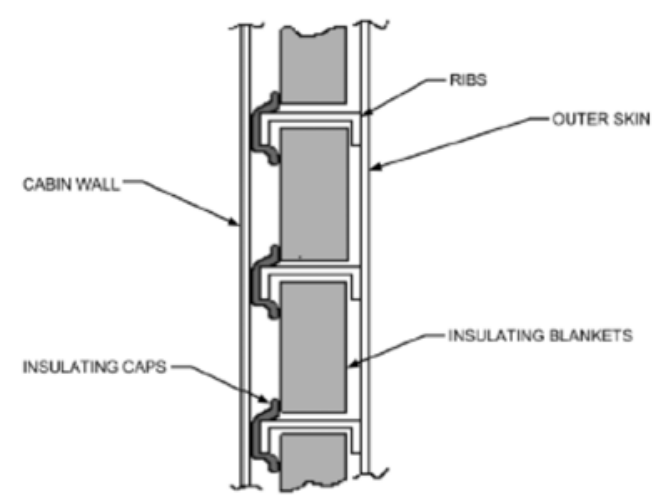

Fig. 1. Example of aircraft insulation arrangement.

For the design of thermal insulation, it is necessary to know the thermal balance of the cabin for the specified operating conditions and expected thermal comfort of passengers. Based on this heat balance, the maximum possible heat transfer coefficient for aircraft cabin will be determined as one of the parameters for thermal insulation. Other parameter is the design constraint - available insulation thickness. The basis for the thermal balance of the cabin is the operating envelope of the airplane, which specifies the environmental conditions under which the aircraft can be operated, Figure 2.

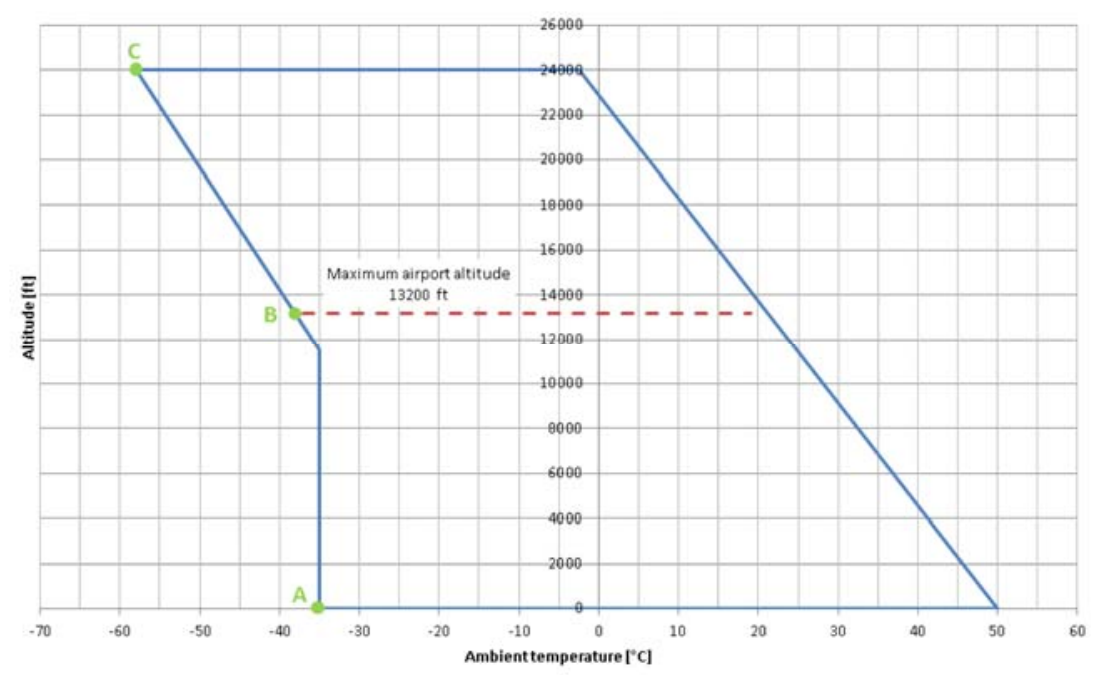

Fig. 2. Operating envelope of the aircraft.

The illustrated points $\mathrm{A}$ and $\mathrm{B}$ define the critical conditions in terms of heating on the ground (point $\mathrm{A}$ for $0 \mathrm{ft}$ altitude, point $\mathrm{B}$ for alpine airport). Point $\mathrm{C}$ is critical for heating during the flight. Cooling is not included, because the aircraft does not have the installed system. The assumption is that heat losses and gains are balanced and constant temperature is maintained in the cabin. Heat balance equation in aircraft cabin can then be written as:

$$
Q_{1}+Q_{2}+Q_{3}+Q_{4}=0
$$


where $Q_{1}$ is personal heat production, $Q_{2}$ is heat from the solar radiation, $Q_{3}$ is heat exchange between the aircraft cabin and environment and $Q_{4}$ is heat delivered by the aircraft heating system.

\subsection{Requirements for thermal insulation}

According to the original proposal composition the thermal insulation was designed and had next parameters for aircraft cabin:

- $\mathrm{U}_{\text {total }}=70 \mathrm{~W} / \mathrm{K}$ during the flight;

- $\mathrm{U}_{\text {total }}=43 \mathrm{~W} / \mathrm{K}$ on the ground.

The analysis shows that these values are sufficient in terms of ensuring a comfortable temperature. However, originally designed insulation has too large thickness, which occupies most of the available space and there is no enough place for noise insulation.

Therefore, it requires the development of new, optimal insulation that meets the requirements for both, heat and noise. Total heat transfer coefficient for the whole cabin is given by the sum of the heat transfer coefficients for individual parts of the cabin (walls, floor, roof, bulkheads, etc.). Heat transfer coefficient for individual part of the cabin is given by the following formula:

$$
U_{\text {part }}=\frac{1}{\frac{1}{\alpha_{\text {int }}}+\sum \frac{c}{\lambda}+\frac{1}{\alpha_{\text {out }}}} \cdot S_{\text {part }}
$$

$U_{\text {part }}$ is heat transfer coefficient of the part of the cabin $[\mathrm{W} / \mathrm{K}], \alpha_{\text {int }}$ is internal convection heat transfer coefficient (cabin interior - airframe) $\left[\mathrm{W} / \mathrm{Km}^{2}\right], \alpha_{\text {out }}$ is outer convection heat transfer coefficient (environment - airframe) $\left[\mathrm{W} / \mathrm{Km}^{2}\right], c$ is the thickness of the insulation layer of the individual part of the cabin $[\mathrm{m}], \lambda$ is the thermal conductivity of the insulation of the individual part $[\mathrm{W} / \mathrm{Km}]$ and $S_{\text {part }}$ is the area of the part of the cabin $\left[\mathrm{m}^{2}\right]$. Insulation can consist of several layers. Characteristic of the insulation appears in fraction $\Sigma c / \lambda$, which expresses the insulation capacity. Following value of $c / \lambda$ was applied for insulation:

- $\quad$ walls, floor, bulkheads, door $\Sigma c / \lambda=1.411\left[\mathrm{~m}^{2} \mathrm{~K} / \mathrm{W}\right]$.

The aim of the development of thermal insulation material is to achieve similar value of $\Sigma c / \lambda\left[\mathrm{m}^{2} \mathrm{~K} / \mathrm{W}\right]$ for these parts with maximum total thickness of the thermal insulation 35 $\mathrm{mm}$, keeping the weight as low as possible. The overall composition of thermal and noise insulation then should not exceed $60 \mathrm{~mm}$.

\section{Characteristics of the basic materials}

A consequence of the analysis of the aircraft is the need to satisfy the technical requirements in terms of thermal and acoustic insulation. To meet these technical requirements, the use of insulating materials between panels and the fuselage is required. In the choice it was preferred to opt for materials already certified in the aeronautical field using as a benchmark for the choice the relationship between weight and performance. Aerocell is a very lightweight, open cell melamine which has exceptional sound absorption proprieties. Skandia exhibits very good thermal properties and contains no fibers. Aerocell is provided in sheets in a variety of thickness. This foam can also be custom cut to suit specific acoustical or thermal requirements. Aerocell is water repellent and it has excellent 
thermal insulation proprieties. The test piece used is $55 \mathrm{~mm}$ in thickness and $100 \mathrm{~mm}$ in diameter. Microlite is a lightweight, flexible, thermal and acoustical insulation material designed to provide the ultimate in noise reduction at minimal weight. Microlite blankets are formed from resin bonded borosilicate 902 bio-soluble glass fibers. Microlite reduces thermal and acoustical transmission in a variety of aerospace applications. These blankets are particularly well suited for insulating the fuselage wall cavities of commercial and business aircraft. Because of their resiliency, high tensile strength and flexibility, Microlite blankets resist settling, breakdown, sagging from vibration, shakedown and damage from impact. Specimens of different thicknesses and $100 \mathrm{~mm}$ in diameter have been tested. Basotect melamine foam is a flexible, open cell foam made from melamine resin, a thermoset polymer. It has high sound absorbing capacity and good thermal insulation properties. Basotect melamine foam inherently has excellent fire, smoke and toxicity (FST) properties that meet rigorous aerospace fire standards. Basotect UL melamine foam can be used for the thermal and acoustic insulation for sidewall panels and bulkhead structures. It makes a positive contribution to the rising demands for better noise reduction while lowering the weight in aircraft construction. In addition, Basotect panels are self-supporting for easy fit and rapid installation. Assembly time of the aircraft can thereby be reduced. The low density and thermal insulation properties as well as the favorable fire properties of Basotect UL melamine foam make it the material of choice for duct insulation. Basotect UL melamine foam is also used for cladding the payload section in the nose cone of rockets for the protection of sensitive satellites from the high acoustic pressure exerted on the rocket during liftoff. Three properties are key features for the use of the thermoset polymer in this application - the lightweight foam has a high sound absorption capacity, is very flexible at a high range of temperatures and is easy to mount and install. Main properties of the samples are summarized in Table 1.

Table 1. Treatments properties.

\begin{tabular}{|c|c|c|c|c|}
\hline $\begin{array}{l}\text { Material } \\
\text { ID }\end{array}$ & $\begin{array}{l}\text { Material } \\
\text { Type }\end{array}$ & Material Name & $\begin{array}{l}\text { Sample Dimensions } \\
\text { [Diameter] [mm] }\end{array}$ & $\begin{array}{c}\text { Sample Nominal } \\
\text { Thickness [mm] }\end{array}$ \\
\hline SA1 & Fiberglass & $\begin{array}{c}\text { Microlite AA } \\
\text { Premium NR } 1.2 \text { pcf } \\
3 / 8^{\prime \prime}\end{array}$ & 100 & 9.52 \\
\hline SA2 & Fiberglass & $\begin{array}{c}\text { Microlite AA } \\
\text { Premium NR } 0.5 \mathrm{pcf} \\
1 "\end{array}$ & 100 & 25.40 \\
\hline SA3 & $\begin{array}{l}\text { Melamine } \\
\text { Foam }\end{array}$ & $\begin{array}{l}\text { Skandia SK-13200 } \\
0.63 \text { pcf 2" }\end{array}$ & 100 & 50.80 \\
\hline SA4 & $\begin{array}{l}\text { Melamine } \\
\text { Foam }\end{array}$ & BASOTEC UL & 100 & 15.00 \\
\hline SA5 & Fiberglass & $\begin{array}{c}\text { Microlite AA } \\
\text { Standard } 0.6 \text { pcf } 2 "\end{array}$ & 100 & 50.80 \\
\hline
\end{tabular}




\section{Thermal characterization}

The whole experimental activity has been carried out in the Department of Industrial Engineering of University of Naples "Federico II" which gained an intense experience within the crucial aspects of internal comfort enhancement, [6-11]. The testing procedure is according to Standard Test Method for Steady-State Heat Flux Measurements and Thermal Transmission Properties by Means of the Guarded-Hot-Plate Apparatus, [12]. This equipment has a control unit comprising a sensing network of thermocouples that measure the contact temperature gradient and the changes in the sample temperature, Figure 3 . The value of the thermal conductivity is characterized by the quantity of heat passing per unit of time per unit area at a temperature drop of $1{ }^{\circ} \mathrm{C}$ per unit length. It depends mainly on the medium's phase, temperature, density, molecular bonding, humidity and pressure. Figure 4 reports the thermal conductivity values of the samples at two temperatures $\left(-40^{\circ} \mathrm{C}\right.$ and 50 ${ }^{\circ} \mathrm{C}$ ), representative of a typical flight thermal envelope.

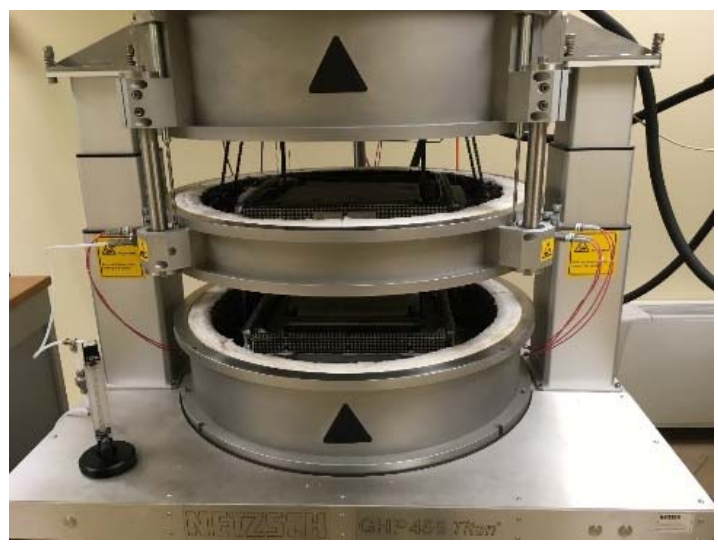

Fig. 3. Thermal test facility (Netzsch GHP 456 Titan).

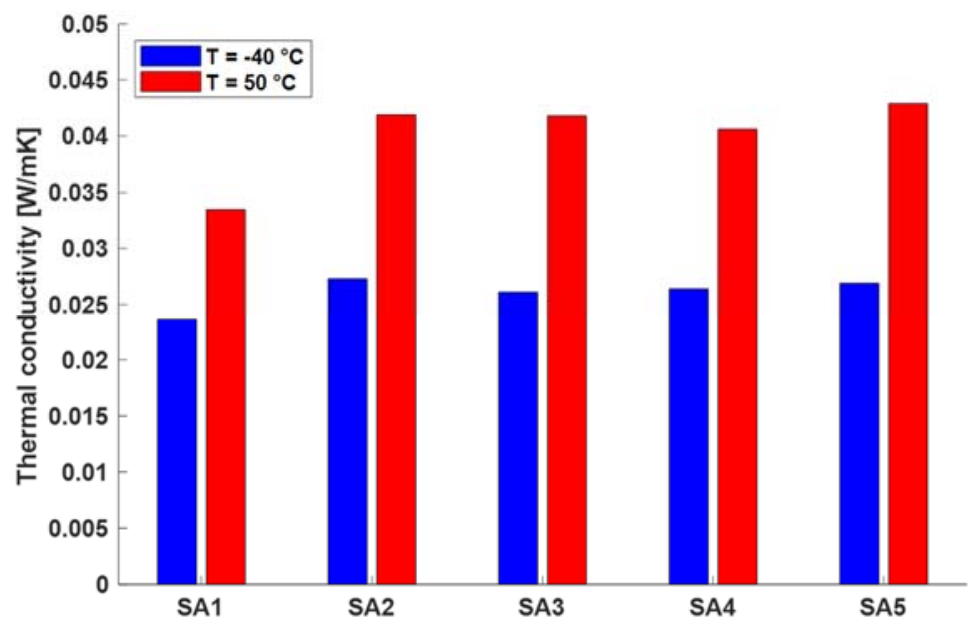

Fig. 4. Thermal test results. 


\section{Conclusions and future studies}

SPAIN Partners have acquired a new design and experimental techniques suitable for the optimization of the noise and thermal levels inside the cabin of EV-55 aircraft. Relying upon the preliminary results of the project, the research team will be involved to define new architectures of the efficient insulation panel suitable for such aircraft, compliant with the technical specification in terms of and weight to performance, and cost to performance aspects as well. Great attention will be given to the integration technology of this solution with the actual interiors configuration with specific focus to maintenance aspects. A set of sandwich configurations have been designed for each specific area of the fuselage to accomplish the overall noise level target. Preliminary experiments have been performed at coupon level and sub-assembly level to confirm the expected outcomes.

This project has received funding from the European Union's Horizon 2020 research and innovation programme under grant agreement No. 714486.

\section{References}

1. P. Liping, Q. Yue, L. Dong, L. Meng, Chinese Journal of Aeronautics, 27(2), 210-216 (2014)

2. S. Park, R. T. Hellwig, G. Grün, A. Holm, Building and Environment, 46(5), 10561064 (2011)

3. Official Clean Sky 2 webpage: http://www.cleansky.eu/

4. Official Evektor company webpage: https://www.evektor.cz/en/ev-55-outback

5. R. Vaicaitis, M. Slazak, NASA Contract Report 172245, Modern Analysis Inc., Ridgewood, New Jersey, December, (1983)

6. M. Viscardi, M. Arena, D. Siano, Int. J. Mech. 10, 329-335 (2016)

7. M. Viscardi, M. Arena, D. Siano, Int. J. Mech. 10, 383-395 (2016)

8. M. Arena, A. De Fenza, M. Di Giulio, A. Paonessa, F. Amoroso, CEAS Aeronaut. J. 8(2), 303-312 (2017)

9. M. Viscardi, M. Arena, D. Siano, Proceedings of 24th international congress on sound and vibration, ICVS24, London, UK (2017)

10. M. Viscardi, P. Napolitano, M. Arena, AIP Conference Proceedings, 1981 (2018), Article number 020100

11. M. Viscardi, M. Arena, CEAS Aeronaut J. (2018), https://doi.org/10.1007/s13272-018$\underline{0326-\mathrm{Z}}$

12. ASTM C177-13, Standard Test Method for Steady-State Heat Flux Measurements and Thermal Transmission Properties by Means of the Guarded-Hot-Plate Apparatus, ASTM International, West Conshohocken, PA (2013) 